\title{
Effects of Room Temperature on Physiological and Subjective Responses to Bathing in the Elderly
}

\author{
Yutaka TochiHara ${ }^{1)}$, Nobuko HashiguCHI ${ }^{2}$, Ikuko YadoGUCHI ${ }^{3)}$, \\ Yumi $\mathrm{KAJI}^{4)}$ and Shigeko SHOYAMA ${ }^{5)}$ \\ ${ }^{1)}$ Department of Human Science, Faculty of Design, Kyushu University, Japan \\ 4-9-1, Shiobaru, Minami-ku, Fukuoka 815-8540 Japan \\ Tel: +81-92-553-4522; Fax: +81-92-553-4522 \\ E-mail: tochi@design.kyushu-u.ac.jp \\ ${ }^{2)}$ Department of Health Science, Faculty of Medicine, Kyushu University, Japan \\ ${ }^{3)}$ ASICS Corporation, Japan \\ ${ }^{4)}$ Department of Internal Medicine, LA $\cdot$ PAZ Hospital, Japan \\ ${ }^{5)}$ Department of Informedia, University of Nagasaki, Japan \\ (received on May 22, 2012, accepted on August 22, 2012)
}

\begin{abstract}
The purpose of this study was to investigate the effect of room temperature on physiological and subjective responses to bathing in the elderly and the young. Dressing room temperatures were 10, 15, 20 and $25{ }^{\circ} \mathrm{C}(50 \% \mathrm{RH})$. Eight healthy young and eight elderly males stayed in the dressing room for 5 minutes, and bathed to a water temperature of $40^{\circ} \mathrm{C}$ for 8 minutes. After bathing, the subjects were exposed to the dressing room for 10 minutes. Systolic blood pressure (SBP), skin temperatures and thermal sensation were measured before, during and after bathing.

In the dressing room, mean skin temperatures of the elderly at 10 and $15^{\circ} \mathrm{C}$ were significantly higher than the young, and the elderly did not complain of the cold in the dressing room or of the hot water as much as the young did. SBPs of the elderly at 10,15 and $20^{\circ} \mathrm{C}$ showed significantly greater increase before and after bathing. On the other hand, there were small increases in SBPs for the young only at 10 and $15^{\circ} \mathrm{C}$. The decreases in SBP of the elderly during bathing were significantly greater than those in the young, especially in a colder dressing room. These physiological and subjective responses during winter bathing put the elderly at high risk of serious complications which lead to drowning in bathrooms. It is recommended that minimum bathroom and dressing room temperatures be higher for the elderly than the young, and between 20 and $25^{\circ} \mathrm{C}$.
\end{abstract}

Keywords: bathing, blood pressure, thermal comfort, elderly, heating system

\section{Introduction}

There were 14,249 accidental home deaths in Japan in 2010 , of which $80.2 \%$ were among people over 65 years old. The most common reason for death was drowning $(4,340)$, and of these $89.0 \%$ involved the elderly (Ministry of Health, Labor and Welfare, 2010). Moreover, $92.4 \%$ of such deaths in Japan occurred in private bathrooms. Previously, most deaths by drowning occurred during the summer in swimming pools, rivers and the sea. Recently, however, the number of deaths by drowning in bathtubs has increased, with a remarkable rise in deaths among the elderly. In 2010, the rate of drowning in bathtubs was $62.5 \%$ of all drowning deaths.

Since reasons for deaths during bathing (Yoshioka et al., 2003) are not only drowning, but also include cardiovascular disease, cerebral hemorrhage, etc., the number of accidental deaths during bathing would be greater than reported. The Tokyo Metropolitan Medical Examiner's Office (2007) estimated the annual number of deaths while bathing in Japan is about 14,000. This number is almost twice the annual number of deaths in traffic accidents in Japan $(7,222)$.

Moreover, there are many reports (Tochihara, 
1999; Takahashi et al., 2007) that a large number of these deaths occur in winter. Funayama and Yamaguchi (1990) reported that mortality in the bathroom in December was about 10 times more than that in July. Ohtsuka et al. (2011) reported that $53 \%$ of accidental deaths in bathtubs occur from November to February.

According to the World Health Organization (1996), however, this large number of deaths by drowning among the elderly is not present in Western countries. Drowning death rates among those over 75 years old are more than 10 times as high in Japan than in Western countries. The Japanese bathing style (Tochihara, 1999 ) in winter, bathing in hot water to the neck in cold environments, might cause this large number of bathing deaths. Therefore, it can be proposed that accidental home death during bathing occurs especially in winter among the elderly in Japan.

Many field studies have shown (Kanda et al., 1995; Ohnaka et al., 2007; Takasaki et al., 2007) that room temperatures in dressing rooms and bathrooms in Japan are low in winter, compared to those of living rooms. Moreover, Japanese people, especially the elderly, take a hot bath almost every day. Therefore, the Japanese elderly are often exposed to cold air and hot water while they are bathing in winter. Since cold exposure and large temperature variations cause physiological burdens and serious health complications, the reason for these accidental deaths in bathtubs might be cold exposure before, during and after bathing, and bathing in very hot water. Nevertheless, although the effects of room temperature on thermal responses for the young during and after hot bathing have been studied in various laboratories (Kanda et al., 1996; Hashiguchi et al., 2002), the number of studies of the elderly is limited. Therefore, though there are several safety guidelines for thermal conditions of the dressing room and bathroom; it is difficult to propose safety guidelines for the elderly.

Hence, the purpose of this study is to investigate the effects of room temperature on physiological and subjective responses to hot bathing in the elderly and the young, and propose safety guidelines for thermal conditions of the dressing room and bathroom for the elderly.

\section{Methods \\ Subjects}

Eight young (21-26 yrs) and eight elderly (65-73 yrs) male volunteers participated in this study. The means and standard errors of their age, height, body weight and body fat percentage $(\%$ Fat $)$ are shown in Table 1. Skinfold thicknesses were measured at triceps, subscapular and abdomen with an Eiken type caliper. Body density was predicted from the Nagamine equation (1975), and \%Fat was computed from body density
Table 1. Physical characteristics of subjects

\begin{tabular}{rrrrrr}
\hline \multicolumn{1}{c}{ Elderly } & & Age** & Height $(\mathrm{cm})^{*}$ & Weight $(\mathrm{kg})$ & \%Fat \\
\hline \multirow{2}{*}{ Yve. } & 69.4 & 162.8 & 59.6 & 20.1 \\
& SE. & 1.1 & 1.9 & 3.0 & 1.8 \\
\hline \multirow{2}{*}{ Young } & Ave. & 22.8 & 171.4 & 56.6 & 16.7 \\
& SE. & 0.6 & 1.3 & 1.2 & 1.4 \\
\hline
\end{tabular}

Significant difference between Elderly and Young

$* ; \mathrm{p}<0.05,{ }^{* *} ; \mathrm{p}<0.01$

\begin{tabular}{|c|c|c|c|c|c|c|}
\hline \multicolumn{3}{|c|}{ Pre-Room } & Dressing & \multicolumn{2}{|c|}{ Bathroom } & $\begin{array}{l}\text { Dressing } \\
\text { Room }\end{array}$ \\
\hline $30 \mathrm{~min}$ & & & 5 min & $8 \min$ & & $10 \mathrm{~min}$ \\
\hline Skin temperature & & & & & & \\
\hline Blood pressure & o & 0 & ० & 0 & ० & 0 \\
\hline Subjective response & es $\Delta$ & $\Delta$ & $\Delta$ & $\Delta$ & $\Delta$ & $\Delta$ \\
\hline
\end{tabular}

Figure 1. Experimental protocol

according to the formula of Brozek et al. (1963). Although there was a significant difference in height between the young and elderly groups, there were no differences in body weight and \%Fat. Before participation, each subject was screened by a medical doctor. All subjects were normotensive, none were taking medicine, or had a history of cardiovascular disease. A medical doctor participated in all of the experiments involving the elderly to check their health. Written informed consent was obtained from all subjects after a full explanation of the study requirements and the risks involved.

\section{Procedure}

Two adjacent climatic chambers and a bathing room were used. One was a pre-room kept at $23^{\circ} \mathrm{C}$. The other was a dressing room kept at 10, 15, 20 or $25^{\circ} \mathrm{C}$ with $50 \%$ relative humidity. After staying more than 30 minutes in the pre-room, physiological and subjective responses were measured for 10 minutes (Figure 1). Thereafter the subjects moved to the dressing room and took off standard clothing $(0.6 \mathrm{clo})$, and stayed there for five minutes. The subjects moved to the bathroom and bathed for eight minutes, immersed to the neck in a Japanese-style bathtub. The water temperature of the bath was kept at $40^{\circ} \mathrm{C}$ which is the average value in Japan (Ohnaka et al., 2007). After bathing the subjects dried themselves with towels, and stayed in the dressing room for another 10 minutes. The subjects wore only shorts in the dressing room and bathroom. The subjects bathed under four thermal conditions on separate days. All the experiments for a particular subject were conducted at the same time of day. The experiments were carried out in spring.

\section{Measurements}

Rectal temperature (Tre) was measured with a thermistor at a depth of $13 \mathrm{~cm}$ from the anal sphincter 
every minute. Skin temperatures at seven local body locations (forehead, abdomen, forearm, hand, thigh, leg and foot) were measured with thermistors every minute. Mean skin temperature (Tsk) was calculated using the following Hardy-DuBois formula (1937).

Tsk $=0.07$ forehed +0.35 abdomen +0.14 lower arm

+0.05 hand +0.19 thigh +0.13 leg +0.07 foot

Blood pressure was obtained at the left-upper arm using an automatic tonometer ((HEM-737, OMRON) as shown in Figure 1. An electrocardiogram using chest electrodes was monitored continuously by a medical doctor during the experiment. Whole body thermal sensations (TS) were also measured during the experiments. TS was rated on a 9 -point scale $(+4$ : very hot, +3 : hot, +2 : warm, +1 : slightly warm, 0 : neutral, -1 : slightly cool, -2 : cool, -3 : cold, -4 : very cold). The subject was allowed to vote between points (e.g. +1.5$)$.

\section{Statistical analysis}

Data are presented as the mean $( \pm \mathrm{SE})$. Results of physiological and subjective data were analyzed by repeated-measures analysis of variance (ANOVA) using SPSS 16.0J for Windows (SPSS Japan Inc., JAPAN) at each time of the measurement. For the ANOVA of the data, the factors were age and temperature. The t-test was used for comparisons between the elderly and young subjects, when the interaction between the age and temperature was significant. As for the Tre and Tsk, statistical analyses were conducted only when the subjective responses were measured. Differences at $\mathrm{p}<0.05$ were significant for all statistical analyses.

\section{Results \\ Rectal temperature and mean skin temperature}

Figure 2 shows changes in Tre for both groups. Each value shows the average for subjects. Rectal temperatures of some subjects were not able to be recorded since the probes were out of their anal sphincter. In the pre-room and the dressing room before bathing, Tre were around $37.2^{\circ} \mathrm{C}$ on average at the 4 room temperatures for both groups, ANOVA shows no significant differences in the Tre among room temperatures and age groups. Changes in Tre during bathing were less than $0.04^{\circ} \mathrm{C}$ on average for all conditions. After bathing, Tre increased by $0.1^{\circ} \mathrm{C}$ on average for all conditions over a period of $10 \mathrm{~min}$.

Figure 3 shows changes in Tsk for both groups. Each value shows the average for eight subjects. Tsk of

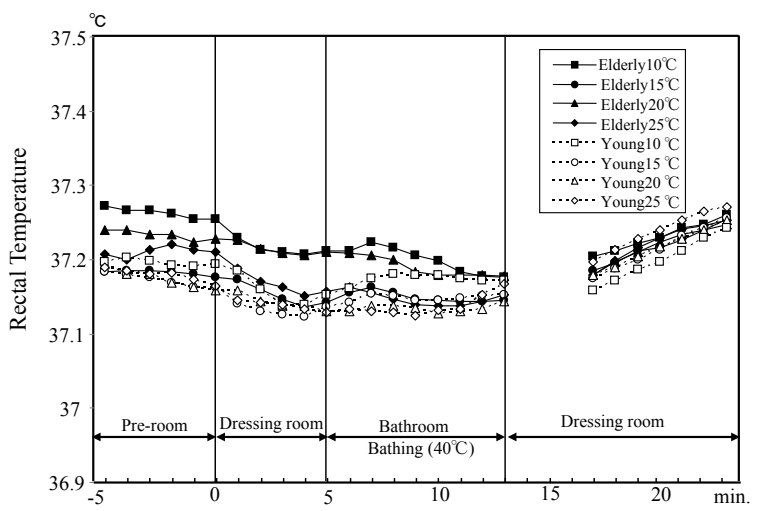

Figure 2. Changes in rectal temperature before, during and after bathing. Values are mean of the 8 subjects except for Young $25^{\circ} \mathrm{C}(\mathrm{n}=7)$ and Elderly $10^{\circ} \mathrm{C}$ $(n=5)$.

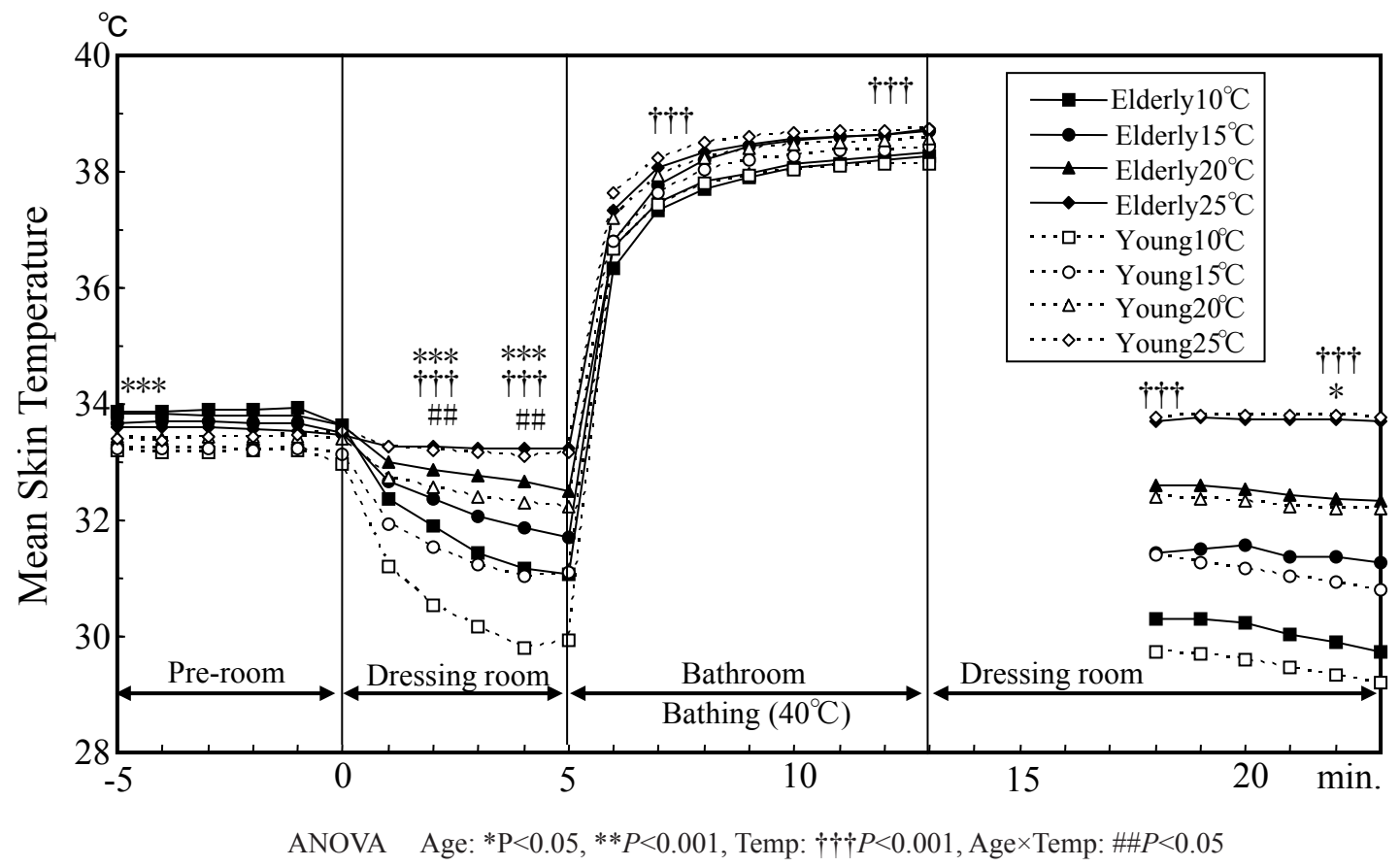

Figure 3. Changes in mean skin temperature before, during and after bathing. Values are mean of the 8 subjects. 
the elderly were significantly $(P<0.001)$ higher than those of the young in the pre-room, but average values of both groups were between 33 and $34^{\circ} \mathrm{C}$. Tsk decreased at all room temperatures in the dressing room. Tsk of both groups increased up to $38.3^{\circ} \mathrm{C}$ during bathing, and decreased again in the dressing room after bathing.

In the dressing room before bathing, ANOVA showed significant $(\mathrm{P}<0.001)$ differences in the Tsk among room temperatures and age groups. There was also significant $(\mathrm{P}<0.01)$ interaction between age group and room temperature. There were no differences in Tsk between the groups at 25 and $20^{\circ} \mathrm{C}$, but Tsk of the elderly were significantly higher than those of the young at $15(P<0.05)$ and $10^{\circ} \mathrm{C}(P<0.001)$. The differences in Tsk between the groups became larger at the lower room temperatures. In the dressing room at $10^{\circ} \mathrm{C}$ before bathing, Tsk of the young and the elderly decreased to $29.8^{\circ} \mathrm{C}$ and $31.2^{\circ} \mathrm{C}$, respectively. This difference was highly significant $(\mathrm{P}<0.001)$.

During bathing, there were significant $(\mathrm{P}<0.001)$ differences in the Tsk among room temperatures, but no difference between groups. In the dressing room after bathing, ANOVA showed significant differences $(P<0.001)$ in the Tsk among room temperatures. At the end of the dressing room, Tsk of the elderly were significantly $(P<0.05)$ higher than those of the young.

\section{Blood pressure}

Figure 4 shows changes in systolic blood pressure
(SBP) before, during and after bathing. Each value shows the average for eight subjects. The average SBP of the elderly was significantly $(P<0.001)$ higher than those of the young during the experiments. At all room temperatures, SBP increased in the dressing room, decreased during bathing, and increased again in the dressing room after bathing. Although there was no significant difference in SBP during bathing among room temperatures, the SBP before and after bathing in the dressing room showed significant $(\mathrm{P}<0.05)$ differences among the room temperatures.

The changes in SBP compared with the values in the pre-room were greater in colder conditions for the elderly than the young. For example at $10^{\circ} \mathrm{C}, \mathrm{SBP}$ in the elderly increased by $40 \mathrm{mmHg}$ in the dressing room, and decreased by $30 \mathrm{mmHg}$ during bathing. These changes were about three times greater than those for the young.

Figure 5 shows the average increase in SBP while in the dressing room before bathing for both groups under four temperature conditions. ANOVA showed SBPs of the elderly and lower room temperatures were significantly $(\mathrm{P}<0.001)$ higher. Moreover, there was a significant interaction $(\mathrm{P}<0.05)$ of age and temperature on the change in SBP. The increases in SBP of the elderly at $10,15,20^{\circ} \mathrm{C}$ were significantly $(\mathrm{P}<0.05)$ higher than those of the young. The differences between the age groups were double. However, there was no difference in SBP changes between the age groups at $25^{\circ} \mathrm{C}$. These results indicate that even a room

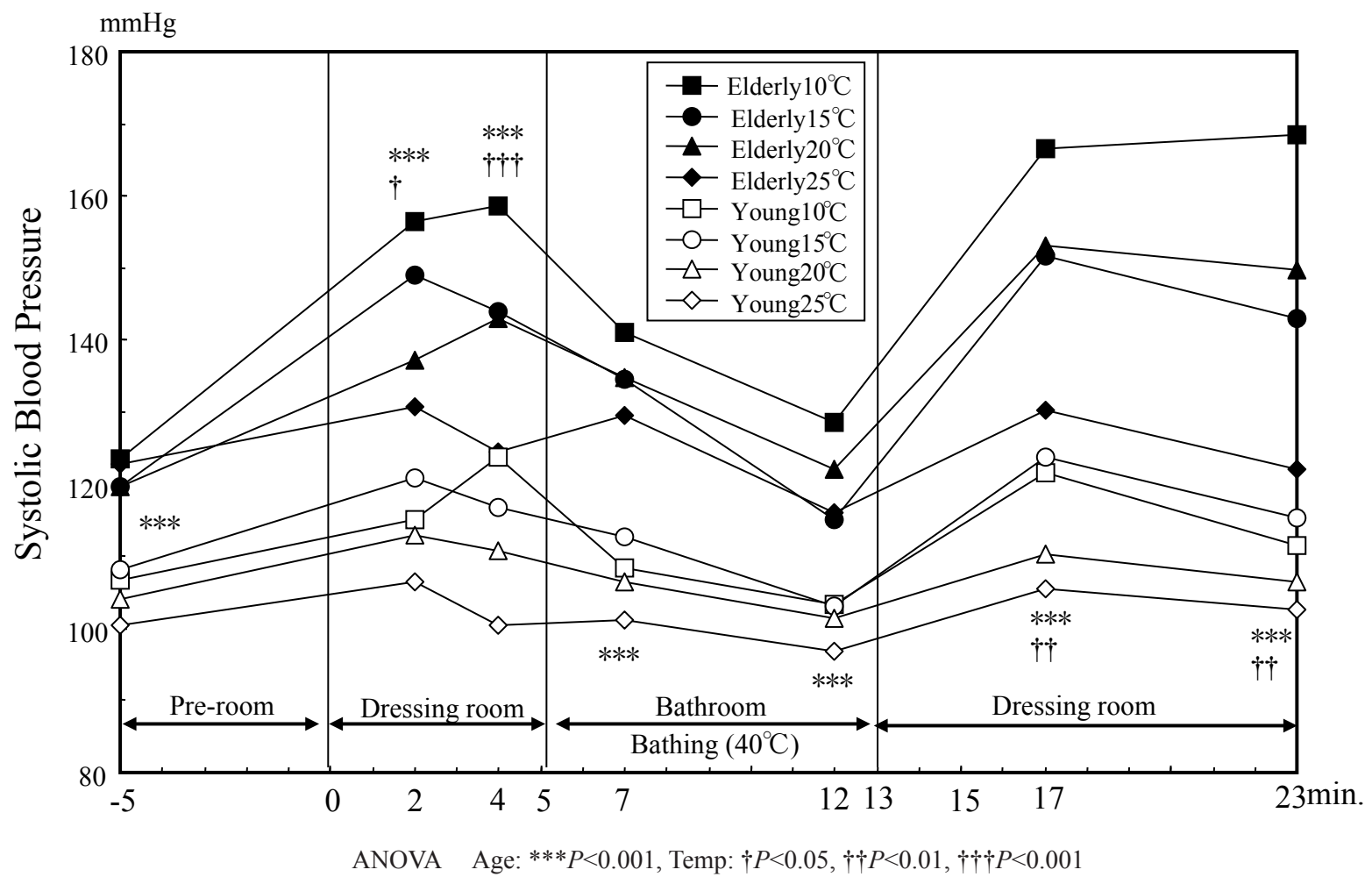

Figure 4. Changes in systolic blood pressure before, during and after bathing. Values are mean of the 8 subjects. 
condition at $20^{\circ} \mathrm{C}$ is a physical burden for the elderly.

\section{Subjective response}

Figure 6 shows changes in TS. In the pre-room, TS was almost "neutral" in both groups. TS changed to cooler under all thermal conditions in the dressing room. TS in both groups became warmer during bathing, and became cooler again in the dressing room after bathing. In the dressing room before bathing, ANOVA showed significant $(\mathrm{P}<0.001)$ differences in TS among room temperatures, and the elderly felt significantly $(\mathrm{P}<0.05)$ warmer than the young. There was a main significant $(\mathrm{P}<0.001)$ effect of age group on TS during bathing, the young indicated their bodies were "warm or hot", while the elderly said "slightly warm".

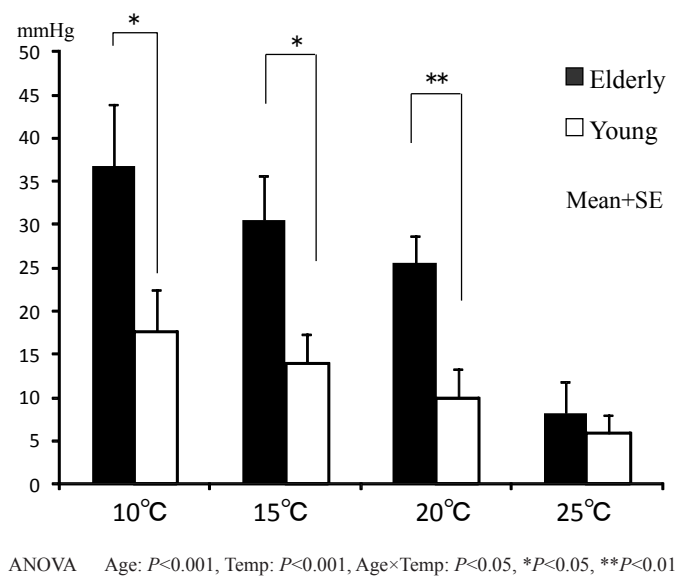

Figure 5. Increase in systolic blood pressure while in the dressing room before bathing. Values are mean and SE.
There were significant main effects of room temperature on TS in the dressing room after bathing.

\section{Discussion}

Japanese people, especially the elderly, take great enjoyment in the Japanese bath, taking one almost every day (Kanda et al., 1995). Their winter bathing style is unique to Japan and its traditional culture (Tochihara, 1999). The style differs from the Western style in the following ways:

1. Japanese people use deep bathtubs, and immerse themselves in a hot bath to the neck.

2. Due to the shortage of heating systems in dressing rooms and bathrooms, room temperatures are low in Japan.

These two differences might cause the large number of accidental deaths due to bathing in winter among the elderly in Japan. Although effects of bathing in hotter water in deep bathtubs on physiological and subjective responses have been reported on both the young (Tochihara et al., 1996; Hashiguchi et at., 2002) and the elderly (Nagasawa et al., 2001; Chishaki et al., 2005: Asakawa et al., 2006), the effects of room temperature on these responses before, during and after bathing have been reported only for the young (Kanda et al, 1996; Hashiguchi et al., 2002).

In the dressing room before and after bathing, the young's thermal sensations and discomfort varied according to room temperature. Room temperature did not influence the elderly as much as the young. They did not complain of cold as much as the young did. The warmer thermal sensation of the elderly might be due to

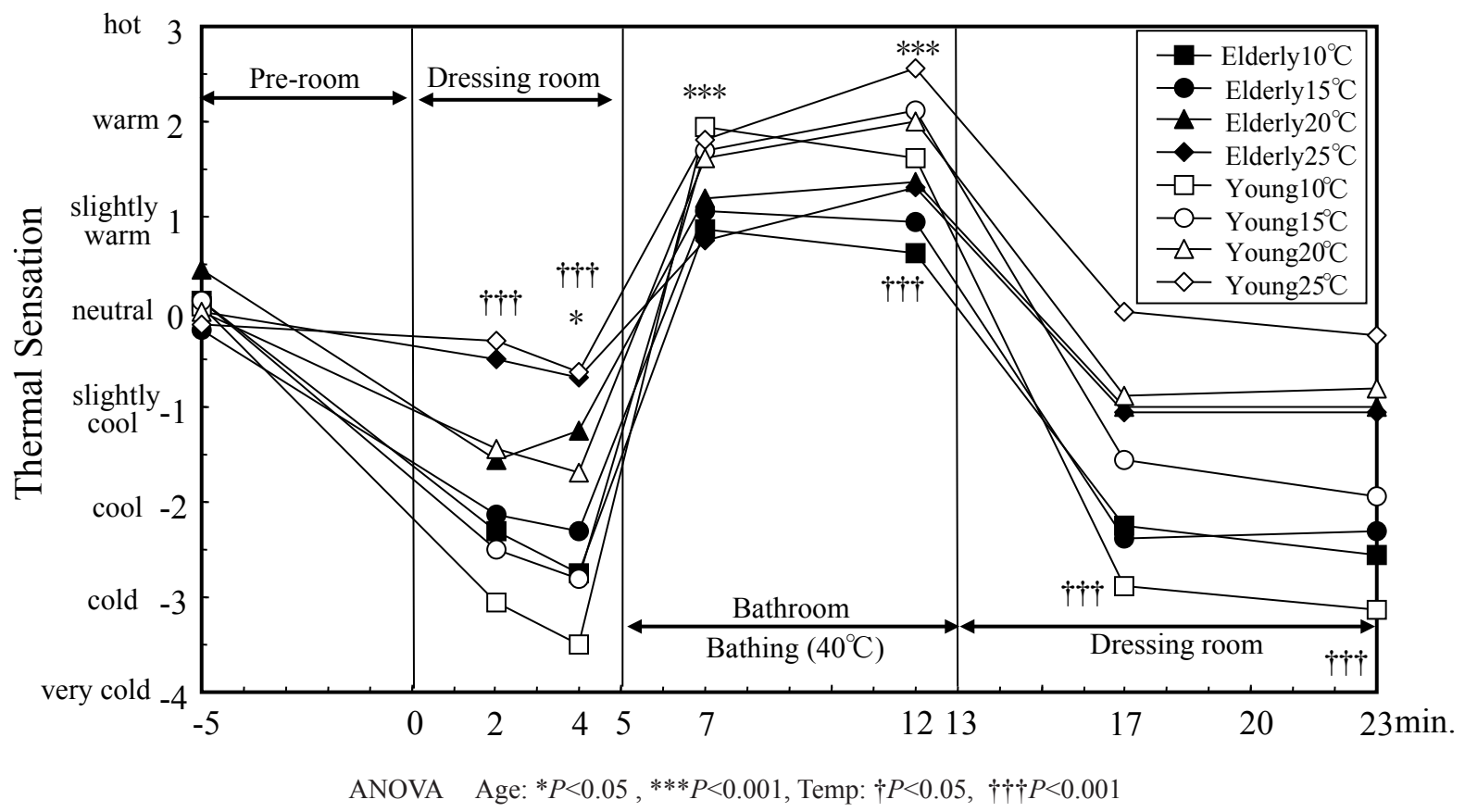

Figure 6. Changes in whole body thermal sensation before, during and after bathing. Values are mean of the 8 subjects. 
the higher Tsk, especially at 10 and $15^{\circ} \mathrm{C}$ (Figure 3). Tochihara et al., (1993) investigated the differences in thermal sensations during cold exposure between the young and the elderly subjects, and reported that the elderly subjects did not feel as cold as the young during early cold exposure. These results indicated that elderly subjects have a reduction in sensitivity to cold. Murata and Iriki (1974) measured the number of cold points in various cutaneous areas for young and elderly subjects, and reported that the number of cold points for the elderly was only half that of the young.

Similarly, the elderly did not complain of hot water during bathing as much as the young did. Tochihara et al. (2011) reported that cutaneous warm thresholds for the elderly were significantly higher than the young at 28 and $22^{\circ} \mathrm{C}$. The elderly need greater heat to detect the sensation of warmth. Collins et al. (1981) measured peripheral temperature discrimination in relation to age, and found the discrimination deteriorated markedly in people over 60 years of age. The decreases in stimuli to the central nervous system from the skin produce these reductions of thermal sensitivity. The elderly's lower degree of discomfort at $10^{\circ} \mathrm{C}$ and in hot water are the results of general reduction of a thermal sensitivity.

Several studies (Hashiguchi et al., 2002; Yamazaki R., 2007) reported that the physiological strains during half-body bathing and bathing in cooler water are less than whole-body bathing and hotter water immersion. However, colder room temperatures made it more difficult to retain body warmth during and after half-body bathing and cooler water immersion. It is particularly important to maintain an acceptable temperature in the dressing room and bathroom in order to bathe comfortably and safely.

It is well-known that low air temperature is associated with a rise in blood pressure (Jansen et al., 2001). There have been several studies which showed a greater increase in blood pressure due to cold in the elderly as compared to younger people (Tochihara et al., 1993; Hashiguchi et al., 2004; Hashiguchi et al., 2011). Collins et al. (1985) studied blood pressure of young and elderly subjects wearing standard clothing (nightwear) at 6,12 and $15^{\circ} \mathrm{C}$, and reported that increases in SBP were significantly greater for the elderly than for the young. Moreover, they found that the SBP of the young at $12^{\circ} \mathrm{C}$ did not increase during the exposure, but the SBP of the elderly increased even at the same room temperature. It was at $15^{\circ} \mathrm{C}$ that the SBP of the elderly did not increase during exposure. Therefore, they suggested that $15^{\circ} \mathrm{C}$ should be the minimum room temperature at which the elderly keep their homes. In this study, the subjects wore only shorts before, during and after bathing, so minimum room temperature should be higher than $15^{\circ} \mathrm{C}$. As shown in Figure 5, the increases in the SBP of the elderly at 10,15 , and $20^{\circ} \mathrm{C}$ were significantly higher than those in the young, but no different at $25^{\circ} \mathrm{C}$. It is believed that less than about $10 \mathrm{mmHg}$ change in SBP at rest is not a burden for the human body. Therefore, for the young, a room temperature of $20^{\circ} \mathrm{C}$ is safe enough to bathe. However, the increase in SBP of the elderly at $20^{\circ} \mathrm{C}$ was about $25 \mathrm{mmHg}$, so $20^{\circ} \mathrm{C}$ is not a safe room temperature for bathing for the elderly. Chiba et al. (2005) measured cardiac responses, such as blood pressure, pulse wave, ECG, of the elderly during actual bathing situations in summer (bathroom temperature was about $25^{\circ} \mathrm{C}$ ) and winter (bathroom temperature was about $20^{\circ} \mathrm{C}$ ). They reported significant and substantial cardiac changes in winter. Therefore, when we decide the minimum temperature of the bathroom and dressing room, the temperature for the elderly should be higher than for the young. A room temperature below $20^{\circ} \mathrm{C}$ is still a physical burden for the elderly.

\section{Conclusions}

In cooler conditions, mean skin temperatures of the elderly before and after bathing were significantly higher than those of the young, and the elderly did not complain of the cold in the dressing room or of the hot water as much as the young did. On the other hand, blood pressure increase before and after bathing, and decrease during bathing of the elderly were significantly greater than those of the young. These physiological and subjective responses during bathing in cold environments put the elderly at high risk of serious complications which lead to drowning in bathrooms. It is recommended that bathroom and dressing room temperatures be higher for the elderly than the young.

\section{References}

Asakawa, Y., Takahashi, R., Endo, F. (2006) Cardiovascular responses during bathing in the elderly (in Japanese with English abstract). Rigakuryoho Kagaku 21: 433-436.

Brozek, J., Grande, F., Anderson, J.T., Keys, A. (1963) Densitometric analysis of body composition; Revision of some quantitive assumptions. Ann NY Acad Sci, 110: 113-140.

Chiba, T., Yamauchi, M., Nishida, N., Kaneko, T., Yoshizaki, K., Yoshioka, N. (2005) Risk factors of sudden death in the Japanese hot bath in senior population. Forensic Science International 149: 151-158.

Chishaki, A., Nagahiro, C., Kim, M., Kobayashi, D., Oguruma R., Fukuda N., Nakata A., Kagawa T., Nagaie T. (2005) Differences between the elderly and youth in circulatory dynamics during bathing (in Japanese with English abstract). Jpn J Cardiovascular Disease Prevention 40: 28-33.

Collins, K.J., Exton Smith, A.N., Dore, C., (1981) 
Urban hypothermia: preferred temperature and thermal perception in old age. British Medical J. 282: 175-177.

Collins, K.J., Easton J.C., and Belfield- Smith, H., Exton-Smith, A.N., Pluck, P.A. (1985) Effects of age on body temperature and blood pressure in cold environments. Clinical Science 69: 465-470.

Funayama, M. and Yamaguchi, Y. (1990) Death of the elderly in the bathroom in Tokyo (in Japanese). Jpn J Public Health Nurse 46: 54-59.

Hashiguchi, N., Ni, F., Tochihara, Y., (2002) Effects of room temperature on physiological and subjective responses during whole-body bathing, half-body bathing and showering. J Physiol Anthropol 21: 277-283.

Hashiguchi, N., Tochihara, Y., Ohnaka, T., Tuchida, C., Otsuki, T. (2004) Physiological and subjective responses in the elderly when using floor heating and air condition systems. J Physiol Anthropol Appl Human Sci. 23: 205-213.

Hashiguchi, N., Kumamoto, T., Chishaki, A., Tochihara, Y. (2011) Effects of vertical air temperature gradients on physiological and psychological responses in the elderly. J Human-Environment System 14: 9-17.

Jansen, PM., Leinweber, MJ., Thien, Th. (2001) The effects of a change in ambient temperature on blood pressure in normotensives. J Human Hypertension 15: 113-117.

Kanda, K., Tsuchiya, J., Seto, M., Ohnaka, T., Tochihara, Y. (1995) Thermal conditions in the bathroom in winter and summer, and physiological responses of the elderly during bathing. Jpn J Hyg 50: 595-603.

Kanda, K., Ohnaka, T., Tochihara, Y., Tsuzuki, K., Shodai, Y., Nakamura. K. (1996) Effects of the thermal conditions of the dressing room and bathroom on physiological responses during bathing. Appl. Human Sci. 15: 19-24.

Ministry of Health, Labor and Welfare, Statistics and Information Department (2010) Vital Statistics Japan

Murata, G., Iriki, M. (1974) Body temperature of the aged - the effect of aging on the cutaneous sensory points (in Japanese with English abstract). Jap. J. Geriat. 11: 157-163.

Nagamine, S., (1975) Evaluation of body fatness by skinfold measurements. JIBP Synthesis 4: 16-20.

Nagasawa, Y., Komori, S., Sato, M., Tsuboi, Y.,
Umetani., K., Watanabe, Y., Tamura, K. (2001) Effects of hot bath immersion on autonomic activity and hemodynamics - Comparison of the elderly patient and the healthy young-. Jpn Circ J. 65: 587-592.

Ohnaka, T., Takasaki, Y., Tochihara, Y., Nahgai, Y., Ito, H., Yoshitake., S. (2007) A survey on thermal conditions of bathroom during winter in Japan (in Japanese with English abstract). J Human and Living Environment, 14: 11-16.

Ohtsuka, Y., Inokuma, S., Sugimoto, H. (2011) Analysis of bathing related accidents in Japan - Collaboration with Japanese Association for Acute Medicine - J Jpn Soc Balneol Climatol Phys Med 74: 239-245.

Takahashi, R., Asakawa, Y., Hamamatsu, A. (2007) Deaths during bating in Japan. J Am Geriatr Soc., 55 : 1305-1306.

Takasaki, Y., Ohnaka, T., Tochihara, Y., Nagai, Y., Ito, H., Yoshitake, S. (2007) Environmental and behavioral conditions of bathing among elderly Japanese. J Physiol Anthropol 26: 235-240.

Tochihara, Y., Ohnaka, T., Nagai, Y., Tokuda, T. and Kawashima, Y. (1993) Physiological responses and thermal sensations of the elderly in cold and hot environments. J. Thermal Biol. 18: 353-361.

Tochihara, Y., Koshimizu, H., Ohnaka, T. (1996) Effects of water and room temperatures on thermal responses during and after bathing. Proceedings of Indoor Air '96. 1, 233-238.

Tochihara, Y. (1999) Bathing in Japan: A Review. J Human Environment System 3: 27-34.

Tochihara, Y., Kumamoto T., Lee, JY., Hashiguchi, N. (2011) Age-related differences in cutaneous warm sensation thresholds of human males in thermoneutral and cool environments. Journal of Thermal Biology 36(2): 105-111

Tokyo Metropolitan Medical Examiner's Office (2007) Annual business report

World Health Organization (1996), World Health Statistics Annual, Geneva, Switzerland,

Yamazaki, R., Honda, Y., Harada, U., Suzuki, Y., Ohtsuka, Y. (2007) Physiological changes by halfbody bathing. J Jpn Soc Balneol Climatol Phys Med 70: 165-171.

Yoshioka, N., Chiba, T., Yamauchi, M., Monma, T., Yoshizaki, K. (2003) Forensic consideration of death in the bathtub. Legal Medicine 5: S375-S381. 
